\title{
The Unemployment Effects of Minimum Wages
}

\author{
Gary S. Fields \\ Cornell University, USA and DELTA, Paris
}

\begin{abstract}
Introduction
This article summarizes the results of a more technical paper [1] on the unemployment effects of a minimum wage or other institutionally-imposed wage floors. By definition, a "wage floor" is the lowest wage that any employer may pay or that any worker may receive. The wage floor may be caused by unions engaging in collective bargaining and raising the wages of their members; governments paying their employees higher wages than they might earn elsewhere; or some other institutional intervention. The type of wage floor analysed in this article is a minimum wage set by the Government above the level that would otherwise have been determined by supply and demand.
\end{abstract}

Figures 1 and 2 present the familiar standard textbook-level diagram of the labour market effects of a minimum wage. This model produces several conclusions:

- A minimum wage causes unemployment. In Figure 1, compare the unemployment when the wage is $W_{1}$ or $W_{2}$ with the full employment when the wage is at the market-clearing level $W^{*}$. Nearly all labour economics textbooks contain this result.

- An increase in the minimum wage induces more labour to move into the covered sector. This is implicit in the upward-sloping labour supply curve.

- The higher the minimum wage, the more unemployment there will be. Unemployment is $L_{1}-E_{1}$ when the minimum wage is $W_{1}$ and $L_{2}-E_{2}>L_{1}-E_{1}$ when the minimum wage is $W_{2}>W_{1}$

- For any given minimum wage, the more elastic the demand for labour, the larger is unemployment. In Figure 2, demand curve $D_{2}$ is more elastic than curve $D_{1}$. For a given minimum wage $W^{\prime}$ and given labour supply curve $S$, the model says that unemployment is greater for curve $D_{2}\left(L^{\prime}-E_{2}\right)$ than for curve $D_{1}\left(L^{\prime}-E_{1}\right)$.

The preceding conclusions derive from a one-sector model which implicitly assumes that the minimum wage applies uniformly to everyone. But empirical evidence suggests otherwise. In a study covering both industrialized and developing countries, Starr [2] reported that the self-employed, service workers, and farm workers are typically excluded from minimum wage coverage. Ashenfelter and Smith [3] found high rates of non-compliance with minimum wages in the United States. Brazil and Mexico regularly report their wage distributions using the categories "less than minimum wage", "one to two minimum wages", etc.[4] and so on. 
Figure 1: The Unemployment Effects of Alternative Minimum Wages

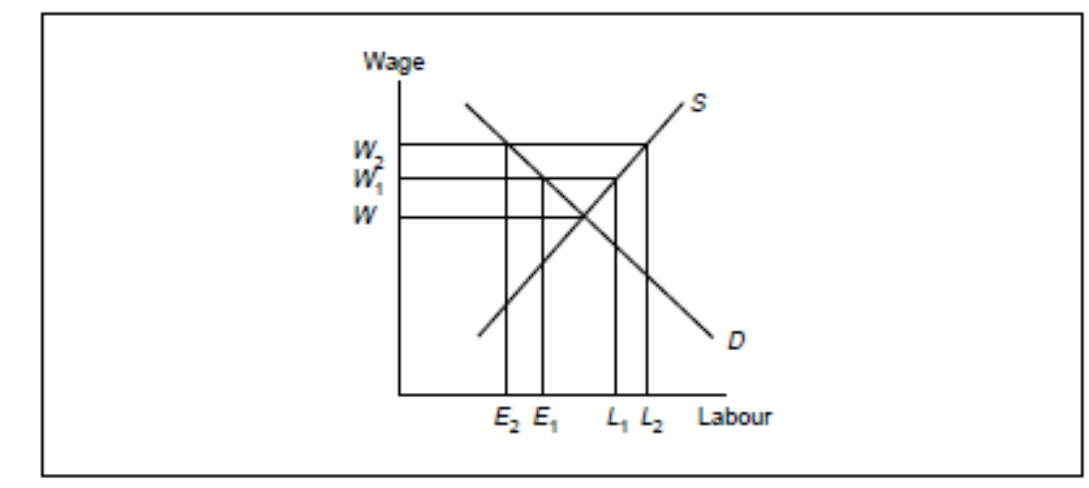

Figure 2: The Unemployment Effects of Alternative Labour Demand Curves

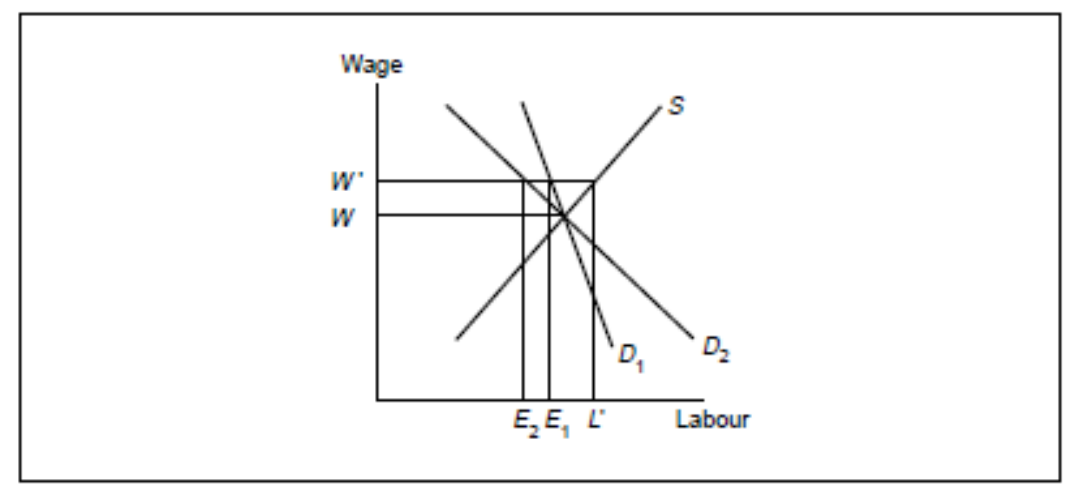

Because coverage and compliance with minimum wages are far from universal, a better stylization than a single-sector model would be a two-sector model, one sector with minimum wage coverage and the other without it. Accordingly, twosector models consisting of a high-wage sector, a low-wage sector, and possible mobility between the two form the basis of the present analysis. Such models were originated by Harris and Todaro [5] and Harberger [6] in the context of dualistic labour markets in developing countries, and were subsequently used by Mincer [7] and Gramlich [8] to analyse the economics of minimum wages in an economy with covered and non-covered sectors.

At first, the results from the two-sector model seemed to support those of the one-sector model. Mincer concluded that "...the unemployment rate induced by the imposition of minimum wages is proportional to the percentage wage gap (w) between the sectors..."[7] Harris and Todaro[5] also led readers to believe that the higher the minimum wage, the more unemployment there would be in equilibrium[9]. Mincer [7] reached another conclusion: that a minimum wage will have a smaller effect on unemployment the less elastic the demand for labour in the covered sector.

The results that follow are less clear-cut. I work with special cases of the more general two-sector model and perform comparative static analysis of the unemployment effects of minimum wages for three parameters of interest:

1. the elasticity of demand for labour in the covered sector; 
2. the elasticity of the wage in the non-covered sector labour force; and

3. the size of the minimum wage.

I show that for none of these parameters is the comparative static effect unidirectional. If special cases of a model give opposing results, the comparative statics must be ambiguous in the general model. Claims in the existing literature of unambiguous comparative static effects cannot therefore be correct [10].

\section{The Two-sector Model}

The two-sector model features wage dualism and unemployment. It is assumed that risk-neutral workers choose their labour market strategies in order to maximize the mathematical expectation of their wages, i.e. the wage adjusted for the probability of employment. The covered and non-covered sectors are assumed to be disjoint in the sense that those working in one sector have no chance of gaining employment in the other sector unless they move there; on- the-job search is ruled out. Any temporary differential between expected wages in the two sectors will be eliminated by intersectoral migration. Thus, in equilibrium, expected wages are equalized across sectors:

$$
E\left(W_{C}\right)=E\left(W_{N}\right)
$$

Firms' demand for labour curves are assumed to be inverse functions of the wage in the sector in question. Following the established literature, labour demand in one sector is assumed to be independent of wages in the other sector.

Prior to the minimum wage, competition in the labour market equalizes wages in the two sectors at a level denoted by $W_{0} . E_{c} O$ workers are employed in the covered sector and the remaining $L-E_{c} O$ members of the labour force are employed in the non-covered sector.

When a minimum wage is imposed on some sectors of the economy but not others, the wage in the covered sector is raised by $\gamma$ per cent:

$$
W_{C}=W_{O}(1+\gamma)
$$

where $\gamma=($ Wc - Wo $) /$ Wo. This lowers employment in the covered sector by $\eta \gamma$ per cent, where $\eta$ is the (arc) wage elasticity of demand for labour in the covered sector evaluated between WO and WC:

$$
E_{C}=E_{C} O(1+\eta \gamma)
$$

The reduction in employment in the covered sector and the higher wage there will affect the expected wage in that sector. Workers will reallocate themselves so that the expected wages in the two sectors are again equalized.

To find how the labour force is divided among employment in the various labour market sectors and unemployment following the imposition of a minimum wage, we need a rule to determine how the covered sector jobs are allocated among those who seek them. These models deal with the case of probabilistic hiring, i.e. the probability of employment 
in the covered sector is ' expressed as the ratio of covered sector employment $\left(E_{c}\right)$ to covered sector labour force $\left(L_{c}\right)$, including both employed and unemployed. Thus

$$
E\left(W_{C}\right)=W_{C}\left(E_{C} / L_{C}\right)
$$

The wage in the non-covered sector, $\mathrm{WN}$, is assumed to adjust to clear the market, so that the supply of non-covered sector workers and the number demanded in that sector are equal. Thus, the equilibrium condition becomes

$$
W_{C}\left(E_{C} / L_{C}\right)=W_{N}
$$

The total labour force is the sum of the covered and non-covered sector labour forces:

$$
L_{C}+L_{N}=L
$$

Unemployment $(U)$ is defined as

$$
U=L_{C}-E_{C}
$$

Combining equations, we obtain

$$
W_{O}(1+\gamma) E_{C} O(1+\eta \gamma) /\left[E_{C} O(1+\eta \gamma)+U=W_{N}\right.
$$

The model is not yet closed, because $W_{N}$ has not yet been specified. I do this by working with alternative special cases of the general model.

The first special case, called Model I, assumes that the wage in the noncovered sector is invariant with respect to the size of that sector's labour force. This assumption would be realistic for a traditional agricultural sector in a landabundant economy in which anyone who wants can find a plot of land, till it, and earn the same amount as others in that sector already earn. It also would be a reasonable approximation of an economy in which the covered sector is very small relative to the non-covered sector so that, within the relevant range, any outflows of labour from the non-covered sector or inflows to it leave the wage in that sector effectively unchanged. Precisely this assumption has been made by a number of authors who have extended the Harris-Todaro model [5] including Fields [11], Anand and Joshi [12], Heady [13], Stiglitz [14], Sah and Stiglitz [15], and Bell [16], among others. Hence in Model I:

$$
W_{N}\left(L_{N}\right)=W_{N} O=W_{O}
$$

A different simplifying assumption defines Model II: total wages in the noncovered sector are assumed not to change with the size of that sector's labour force. This could happen in the classic labour surplus situation of the type modelled by Lewis [17] and Fei and Ranis [18], in which labour in the noncovered sector has zero marginal product, and instead is 
paid its average product. If we denote the total fixed output in the non-covered sector by $Q$, then, under the average product rule, the wage in the non-covered sector is

$$
W_{N}=Q / L_{N}
$$

This same expression can be derived in a very different way. Suppose labour is not in surplus and that the production function is given by $Q_{N}=\Phi\left(K_{N} \ln L_{N}\right.$. If $K_{N}$ and $P_{N}$, the price of the product, are fixed over the relevant range, then the marginal product is $\partial Q_{N} / \partial L_{N}=\Phi\left(K_{N}\right) / L_{N}$ and the value of the marginal product of labour in the non-covered sector equals $P_{N} \Phi\left(K_{N}\right) / L_{N}$ Denoting $P_{N} \Phi\left(K_{N}\right) / L_{N}$ by $Q$ and equating the value of marginal product to the wage, we obtain

$$
W_{N}=Q / L_{N}
$$

which is of the same form as (10) but derived very differently.

We thus have two special cases of the general two-sector model: Model I, consisting of equations (1)-(8) and (9), and Model II, consisting of (1)-(8) and (10). We turn now to the comparative static results in these two models.

\section{Results of the Model}

Five results follow. Intuitive explanations are stated here (see Fields [1] for the proofs).

\section{The Effect of a Minimum Wage on Unemployment}

Proposition 1: A minimum wage causes unemployment.

A quick look at the equilibrium condition (5) makes this clear: $W c>W N$ implies that $E c / L c<1$. That is, $L c$ workers supply their labour to the covered sector, but only EC are employed; the rest are unemployed.

\section{The Direction of Labour Movement}

Proposition 2. A sector-specific minimum wage induces movement of labour out of the covered sector if the demand for labour in the covered sector is sufficiently elastic, and into the covered sector if the demand for labour is sufficiently inelastic. Credit for this result is due to Mincer [7], although Harris and Todaro [5] and Corden and Findlay [19] had raised the issue earlier.

This implies that the standard textbook mode is misleading when it assumes that the supply curve of labour to the covered sector is always upward-sloping. Proposition 2 can be seen by rewriting (8) as

$$
W_{O} E_{C} O\left(1+\gamma+\eta \gamma+\eta \gamma^{2}\right)=W_{N} L_{C}
$$

If the term in parentheses is greater than 1 , then $W_{N} L_{C}$ must increase as a result of the minimum wage, which can happen only if labour moves into the covered sector. By similar reasoning, if the term in parentheses is less than one, labour must be moving out of the covered sector. It can be verified that this will happen as $\eta>=<-\frac{1}{1+\gamma}$. 


\section{Elasticity of Demand for Labour in the Covered Sector}

Proposition 3: Given a minimum wage and an elasticity of wage in the noncovered sector with respect to the size of that sector's labour force, a greater elasticity of demand for labour in the covered sector may result either in less unemployment or in more unemployment in equilibrium, depending on parameter values.

A more elastic demand for labour in the covered sector results in less unemployment in Model I. Looking at (5), if Wc and $W_{N}$ are constant, a larger reduction in $E C$ implies an even larger reduction in $L C$ and thus a reduction in unemployment. The opposite result may be derived in Model II. By choosing appropriate parameter values, it can be shown that a more elastic demand for labour might result in more unemployment. An example appears in Fields [1].

Because these are special cases of the same general model, the general model itself necessarily has ambiguous comparative static effects, as stated in Proposition 3.

\section{Elasticity of the Wage in the Non-covered Sector with Respect to the Non-covered Sector Labour Force}

When a minimum wage is imposed, the wage in the non-covered sector will change inversely with the size of that sector's labour force when either: (1) employers in that sector have downward-sloping labour demand curves, or (2) the sector consists of self-employed workers whose marginal products are smaller than their average products. The comparative static question is when will the unemployment resulting from the wage floor be higher - when the wage in the non-covered sector is relatively elastic or relatively inelastic with respect to the size of the non-covered sector labour force? In answer, we have the following proposition:

Proposition 4: Given a minimum wage and an elasticity of demand for labour in the covered sector, a greater elasticity of the wage in the non-covered sector with respect to the size of that sector's labour force may result either in more unemployment or in less unemployment in equilibrium, depending on parameter values.

The intuition for this result is that when the minimum wage induces movement of labour into the covered sector, then, the more the wage in the noncovered sector rises as people move out, the smaller will be the gain from moving, and so the smaller will be the number of people who do so. This means that fewer people will be seeking a given number of covered sector jobs, and therefore the lower unemployment in equilibrium. But, if conditions are such that the minimum wage induces movement of labour into the non-covered sector, then the more the wage in the non-covered sector falls as people move in, the smaller the gain from moving. As a result, more people will stay in the covered sector and fewer people will move into the non-covered sector, which causes unemployment to be higher in equilibrium. Unemployment can be higher or lower because the more elastic the non-covered sector wage with respect to the size of that sector's labour force, the more moderate the response of unemployment to the minimum wage. 


\section{Size of the Minimum Wage}

Proposition 5: Other things being equal, a higher minimum wage may result either in more unemployment in equilibrium or in less unemployment in equilibrium, depending on parameter values.

More unemployment would assuredly arise if a higher minimum wage causes both an increase in the quantity of labour supplied to the covered sector and a decrease in the quantity of labour demanded. As stated in Proposition 2 , the quantity of labour supplied to the covered sector will rise provided that the demand for labour in the covered sector is sufficiently inelastic. But if that is not the case, a higher minimum wage can reduce the amount of labour supplied to the covered sector. If the demand for labour in the covered sector is elastic enough, so many jobs may be lost and so many job-seekers discouraged that unemployment may actually decrease. The requisite elasticity condition and an illustrative example appear in Fields [1].

Thus, contrary to the textbook labour market model, we find that a higher minimum wage can result either in more unemployment in equilibrium or in less unemployment in equilibrium, depending on parameter values.

\section{Conclusion}

This article has discussed several theoretical ambiguities which arise when a minimum wage applies to part but not all of a country's labour market. Because theoretical reasoning alone does not suffice to determine whether unemployment will increase or decrease in response to a change in the minimum wage or in other parameters of interest, empirical estimates are needed. But it would be a mistake to try to estimate the parameters of the simple two-sector model shown earlier. Empirical analysis for the real world must be based on a more refined model which allows for such additional labour market phenomena as job fixity, heterogeneous labour, preferential hiring, and on-the- job search, all in a multiperiod context.

While much more remains to be worked out, what we can say at this point is that the predictions derived from the

textbook model definitely do not carry over to the two-sector case. Therefore, since a non-covered sector exists nearly everywhere, the predictions of the textbook model simply cannot be relied on.

Finally, it is worth emphasizing that one's views about the desirability of a minimum wage ought to depend on more than the size of the unemployment effect alone. A thoroughgoing welfare economic analysis is needed. Looking at the literature, one is struck by how seldom this is even attempted.

\section{Notes and References}

1. Fields, G.S., "Wage Floors and Unemployment: A Two-sector Analysis", paper presented at the International Conference on the Economics of Low Pay and the Effects of Minimum Wages, Arles, France, 1993.

2. Starr, G., Minimum Wage Fixing, International Labour Organization, Geneva, 1981.

3. Ashenfelter, O. and Smith, R.S., "Compliance with the Minimum Wage", Journal of Political Economy, Vol. 87 
No. 2, April 1979, pp. 333-50.

4. And, unfortunately, in these countries, the most frequently observed category is "less than one minimum wage".

5. Harris, J.R. and Todaro, M.P., "Migration, Unemployment and Development: A Two-sector Analysis", American Economic Review, Vol. 60 No. 1, March 1970, pp. 126-42.

6. Harberger, A.C., "On Measuring the Social Opportunity Cost of Labour", International Labour Review, Vol. 103 No. 6, June 1971, pp. 559-79.

7. Mincer, J., "Unemployment Effects of Minimum Wage", Journal of Political Economy, Vol. 84 No. 4, part 2, July-August 1976, pp. S87-S104.

8. Gramlich, E.M., "Impact of Minimum Wages on Other Wages, Employment, and Family Incomes", in Okun, A.M. and Perry, G.L. (Eds), Brookings Papers on Economic Activity 2, Brookings Institution, Washington, DC, 1976, pp. 409-51.

9. Although in footnotes they acknowledged that this conclusion is based more on plausible parameter values than on theoretical necessity.

10. Because such ambiguities are shown to arise in the single-period special cases of Mincer[7] and Gramlich's[8] models, the more complicated multi-period features of their models are not needed.

11. Fields, G.S., "Rural-Urban Migration, Urban Unemployment and Underemployment, and Job Search Activity in LDCs", Journal of Development Economics, Vol. 2 No. 2, June 1975, pp. 165-87.

12. Anand, S. and Joshi, V, "Domestic Distortions, Income Distribution and the Theory of Optimum Subsidy", The Economic Journal, Vol. 89 No. 354, June, 1979, pp. 336-52.

13. Heady, C.J., "Shadow Wages and Induced Migration”, Oxford Economic Papers, Vol. 33 No. 1, March 1981, pp. 108-21.

14. Stiglitz, J.E., "The Structure of Labor Markets and Shadow Prices in LDCs", in Sabot, R.H. (Ed.), Migration and the Labor Market in Developing Countries, Westview Press, Boulder, CO, 1982.

15. Sah, R.K. and Stiglitz, J.E., "The Social Cost of Labor and Project Evaluation: A General Approach", Journal of Public Economics, Vol. 28 No. 2, November 1985, pp. 135-63.

16. Bell, C., "Regional Heterogeneity, Migration, and Shadow Prices", Journal of Public Economics, Vol. 46 No. 1, October 1991, pp. 1-27.

17. Lewis, WA., "Economic Development with Unlimited Supplies of Labor", The Manchester School, Vol. 22 No. 2, May 1954, pp. 139-91. 
18. Fei, J.C.H. and Ranis, G., Development of the Labor Surplus Economy, Irwin, Homewood, IL, 1964.

19. Corden, WM. and Findlay, R., "Urban Unemployment, Intersectoral Capital Mobility, and Development Policy", Economica, Vol. 42 No. 165, February 1975, pp. 59-78. 